\title{
Removing Lead and Cobalt Ions from Aqueous Solution by
}

\section{Hydroxyapatite Adsorbent}

\section{Vahdat A*, Ghasemi B and Yousefpour M \\ Faculty of Metallurgical and Materials Engineering, Semnan University, Iran}

*Corresponding author: Armin Vahdat, Faculty of Metallurgical and Materials Engineering, Semnan University, Semnan, Iran, Tel: +989358402002; Email: armin.vahdat0098@gmail.com

\section{Research Article}

Volume 4 Issue 2

Received Date: June 24, 2019

Published Date: June 29, 2019

DOI: $10.23880 /$ nnoa- 16000164

\section{Abstract}

In the current study, to recover and remove lead and cobalt ions from an aqueous solution, hydroxyapatite (HAp) and magnetic nanocomposite of HAp were used. For this purpose, chicken thighbone was used as the starting material. Lead and cobalt ion adsorption process was performed discontinuously within the temperature range $25-55^{\circ} \mathrm{C}$, contact time 5 $120 \mathrm{~min}$, adsorbent dose $0.25-5 \mathrm{~g} / \mathrm{L}$, and $\mathrm{pH} 2-9$. Under optimum conditions, the maximum ions adsorption efficiency using hydroxyapatite (HAp) and magnetic nanocomposite of HAp was determined to be $93.75 \%$ and $96.11 \%$ for lead and $90.48 \%$ and $94 / 72 \%$ for cobalt, respectively. FTIR, SEM, and EDS analyses were applied to characterize the adsorbents.

Keywords: Hydroxyapatite; Aqueous solution; Lead Ion; Cobalt Ion; Magnetic Composite

\section{Introduction}

Most of the metal ions are carcinogens and lead to serious health concerns by producing free radicals. Hence, fast and accurate detection of metal ions has become a critical issue. Among various metal ions arsenic, cobalt, lead, mercury and chromium are considered to be highly toxic $[1,2]$. Heavy metals can enter a water supply by industrial and consumer waste, or even from acidic rain breaking down soils and releasing heavy metals into streams, lakes, rivers, and groundwater [5]. Lead and cobalt ions are of the most common hazardous metal ions which are found in various sewage industries. These ions can cause deaths in plants and animals and many diseases in the human body [6,7]. The authorized amount of these ions has been reported $50 \mu \mathrm{g} / \mathrm{L}$ and $15 \mu \mathrm{g} / \mathrm{L}$ by the World Health Organization (WHO) and the Environmental Protection Agency (EPA), respectively [8]. In order to recover and remove heavy metal ions from aqueous solutions, there are several methods such as chemical treatments, ion changes, flocculation, membrane processes, and electrochemical and adsorption techniques $[9,10]$. Among these methods, the adsorption method is widely applied considering its ease of implementation and low cost [11]. To recover and remove lead and cobalt ions, various adsorbents such as magnetic nanoparticles, algae biomass, sodium montmorillonite and calcium montmorillonite [12], activated carbon, fungi, magnetic hydrogels, and rice peel [6] have been used. However, today research is underway in finding adsorbents of lower cost and higher capacity.

Hydroxyapatite is one of the substances used in soil and sewage because of its adsorption properties in various fields such as drug release, chromatography, and heavy metal ion adsorption [13]. This substance is effective in recovery and removal of many toxic heavy metal ions such as lead, cobalt, nickel, zinc, copper, cadmium, and uranium from aqueous solutions [14]. This material has a good buffering feature and low solubility in water and has a high stability during oxidation, which 


\section{Nanomedicine \& Nanotechnology Open Access}

makes it a suitable material for the recovery of metal ions from aqueous solutions [15].

Although the previous investigations have studied removal of heavy ions from aqueous solutions [16-20], but no report is available on the effect of processing parameters such as initial $\mathrm{pH}$, temperature, contact time, the initial concentration of lead and cobalt ions and adsorbent dose on the efficiency of the adsorption process.

\section{Materials and Methods}

\section{Preparation of Lead and Cobalt Solution}

A stock solution of $\mathrm{Pb}$ (II) with an initial concentration of $1000 \mathrm{mg} / \mathrm{L}$ was prepared by dissolving $1.6 \mathrm{~g}$ of lead nitrate $\left(\mathrm{Pb}\left(\mathrm{NO}_{3}\right)_{2}\right)$ in 1 liter of distilled water. After preparing a stock solution, it was diluted with distilled water in order to prepare solutions with a specific concentration of lead ions for the adsorption process. To adjust the initial $\mathrm{pH}$ of the solutions, sodium hydroxide and hydrochloric acid solutions at $1 \mathrm{M}$ concentration were used. The materials were used without any purification. Also, for preparing that of cobalt, A stock solution of Co (II) was prepared by dissolving lead nitrate $\left(\mathrm{Pb}\left(\mathrm{NO}_{3}\right)_{2}\right)$ in 1 liter of distilled water.

\section{Adsorbent Preparation}

To prepare HAp, chicken bones were washed with distilled water for $45 \mathrm{~min}$ to remove grease and other material. Then, bones were exposed to a direct flame to be carbonized completely. Carbonated bones were heated at $1000^{\circ} \mathrm{C}$ for $4 \mathrm{~h}$ through the calcination process. The calcined bones were cooled to ambient temperature and powdered via the milling process.

A chemical deposition method was used to produce the $\mathrm{HAp} / \mathrm{Fe}_{3} \mathrm{O}_{4}$ magnetic nanocomposite. To synthesize $\mathrm{HAp} / \mathrm{Fe}_{3} \mathrm{O}_{4}$ nanocomposite, a solution with the 2:1 molar ratio of Fe (III) to Fe (II) was prepared. After preparing the solution, $1 \mathrm{~g}$ of the prepared HAp was added to it and was stirred for 20 min to provide Fe (III) and Fe (II) on the surface of HAp. At the end of this period, sodium hydroxide solution $(1.5 \mathrm{M})$ was added to the mixture at a temperature of $70-80^{\circ} \mathrm{C}$ and was stirred for $50 \mathrm{~min}$ [15] The produced magnetic nanocomposite was separated from the solution using a magnetic field (magnet) and washed several times with distilled water to be completely neutralized. After neutralization, it was placed in an oven for $24 \mathrm{~h}$ at a temperature of $100^{\circ} \mathrm{C}$ to dry and then produce the powder.

\section{Analytical Techniques}

To investigate the functional groups in the prepared $\mathrm{HAp}$ and $\mathrm{HAp} / \mathrm{Fe}_{3} \mathrm{O}_{4}$ magnetic nanocomposite before and after the lead and cobalt ion adsorption process, an infrared spectrometer analysis (FTIR, Bruker, Tensor27) was used in the wavelength range of $400-4000 \mathrm{~cm}-1$. The surface morphology and elemental analysis of adsorbents were investigated before and after the adsorption process by scanning electron microscopy (SEM) (MIRA3-FEG, TESCAN, Czech) equipped with an Energy dispersive spectroscopy (EDS) detector.

\section{Adsorption Studies}

The adsorption process was performed discontinuously in batch mode and the effects of parameters such as initial $\mathrm{pH}$, temperature, contact time, and adsorbent dose were studied. The effects of $\mathrm{pH}$ on adsorption efficiency of lead and cobalt ions using the mentioned adsorbents were investigated in the $\mathrm{pH}$ range of 2-9. The initial $\mathrm{pH}$ of the samples was determined using $1 \mathrm{M} \mathrm{HCl}$ and $\mathrm{NaOH}$ solution and $\mathrm{pH}$ of the samples was measured using a digital $\mathrm{pH}$ meter (Metrohm 744). After determining the optimal initial $\mathrm{pH}$, other parameters such as temperature $\left(25-55^{\circ} \mathrm{C}\right)$, contact time (5-120 min), and adsorbent dose $(0.25-5 \mathrm{~g} / \mathrm{L})$ at optimal $\mathrm{pH}$ were investigated and the best adsorption percentage was used for determining the optimal conditions. After the adsorption process, the residual concentration of the ions in aqueous solutions was determined using the atomic adsorption spectrometry (SpectrAA-10 plus, Varian Co) with acetylene-air fuel. In all samples the removal percentage of lead and cobalt ions (R\%) and adsorption capacity (qe) were obtained from Eqs. 1 and 2, respectively:

$$
\begin{gathered}
\mathrm{R}(\%)=\left(\left(\mathrm{C}_{-} 0-\mathrm{C}_{-} \mathrm{i}\right) / \mathrm{C}_{-} \mathrm{i}\right) \times 100(1) \\
\text { q_e }=\left(\left(\mathrm{C}_{-} 0-\mathrm{C}_{-} \mathrm{i}\right) / \mathrm{W}\right) \times \mathrm{V}(2)
\end{gathered}
$$

where $\mathrm{Co}$ and $\mathrm{Ci}(\mathrm{mg} / \mathrm{L})$ are the initial and equilibrium concentration of the ions, respectively, $\mathrm{V}$ is solution volume (L), $\mathrm{W}$ is the mass of the adsorbent (g), $\mathrm{R} \%$ is the removal percentage of the ions, and qe is adsorption capacity of used adsorbent (mg/g).

\section{Results and Discussion}

\section{Investigation of Adsorbent Properties}

The FTIR analysis of the HAp produced from chicken bone and $\mathrm{HAp} / \mathrm{Fe}_{3} \mathrm{O}_{4}$ nanocomposite before and after the lead and cobalt ions adsorption process is shown in Figure 1 and 2. In the FTIR analysis of HAp and 


\section{Nanomedicine \& Nanotechnology Open Access}

$\mathrm{HAp} / \mathrm{Fe}_{3} \mathrm{O}_{4}$ nanocomposites, a peak is observed in the range of $3,436 \mathrm{~cm}^{-1}$ and $3,435 \mathrm{~cm}^{-1}$, respectively, which is attributed to the vibrations and stretching of the $\mathrm{O}-\mathrm{H}$ groups of hydroxyl groups [18]. The results of the IR analysis in $\mathrm{HAp}$ and the $\mathrm{HAp} / \mathrm{Fe}_{3} \mathrm{O}_{4}$ nanocomposite in the range of $569 \mathrm{~cm}^{-1}, 1,044 \mathrm{~cm}^{-1}$, and $1,047 \mathrm{~cm}^{-1}$ show some peaks that can be related to tensile vibrations of PO43- in the HAp [21]. Between the wavelengths $2,920 \mathrm{~cm}^{-1}$ and $2,922 \mathrm{~cm}^{-1}$, some peaks are observed that are due to vibrations of $-\mathrm{CH}_{2}$ in the adsorbents [22]. The peak at $1,632 \mathrm{~cm}^{-1}$ is indexed to vibration and tensile motion of $\mathrm{C}=0$ [22]. After the formation of $\mathrm{HAp} / \mathrm{Fe}_{3} \mathrm{O}_{4}$ magnetic nanocomposite, the peak at $569 \mathrm{~cm}^{-1}$, which is attributed to the HAp structure, was shifted to $570 \mathrm{~cm}^{-1}$. This peak shift in the structure of HAp can be due to the vibration of $\mathrm{Fe}-\mathrm{O}$ in the structure of the magnetic nanocomposite [23]. The FTIR analysis after adsorption of lead metal ions shows no significant change after adsorption on the intensity and location of the peaks. Hence, it is inferred that the adsorption of lead metal ions on the surface of the adsorbents is physical, probably due to the weak electrostatic interactions and Van der Waals forces. However, the location of the peaks for the cobalt ion were changed which can be attributed to the interaction of the functional groups and the cobalt ion.

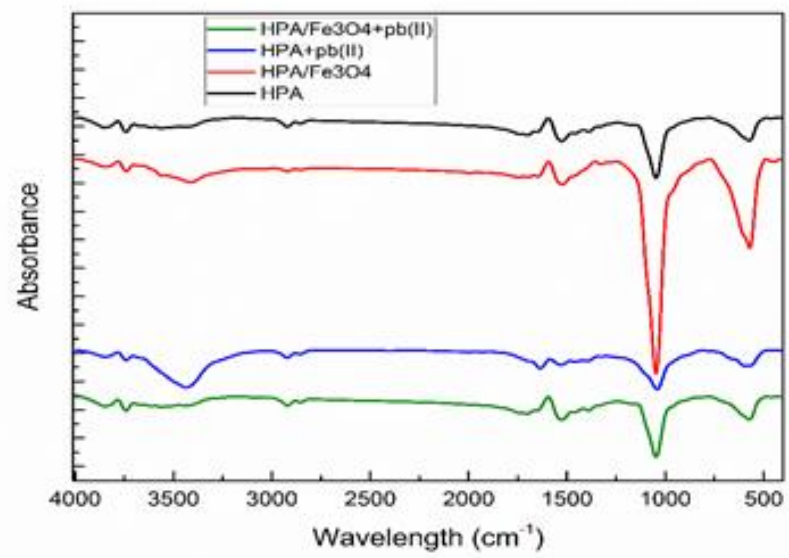

Figure 1: FTIR spectra of hydroxyapatite and hydroxyapatite $/ \mathrm{Fe}_{3} \mathrm{O}_{4}$ nanocomposite before and after lead ion adsorption from aqueous solution.

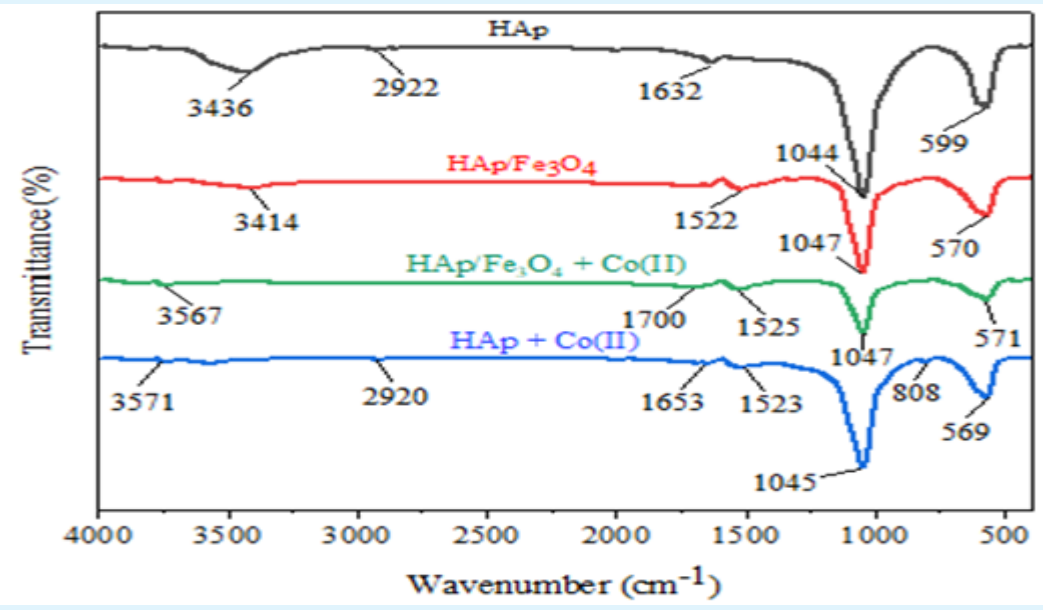

Figure 2: FTIR spectra of hydroxyapatite and hydroxyapatite $/ \mathrm{Fe}_{3} \mathrm{O}_{4}$ nanocomposite before and after cobalt ion adsorption from aqueous solution. 


\section{Nanomedicine \& Nanotechnology Open Access}

SEM analysis was used to investigate the surface and morphological changes of $\mathrm{HAp}$ and $\mathrm{HAp} / \mathrm{Fe}_{3} \mathrm{O}_{4}$ magnetic nanocomposite before and after the lead and cobalt ion adsorption process the results show that the adsorbents have irregular and porous structures and consist mainly of fine particles and spherical particles, which are shown in Figures 3 and 4, respectively. The pores and grooves on the adsorbent surface can be effective in the interaction and adsorption of heavy metal ions. After the adsorption of lead and cobalt ions, due to the adsorption and placement of lead ions, the grooves and pores are occupied. The surfaces of $\mathrm{HAp}$ and $\mathrm{HAp} / \mathrm{Fe}_{3} \mathrm{O}_{4}$ adsorbents after lead and cobalt ions adsorption are shown in Figures 3C and 3D and 4C and 4D, respectively.

Elemental analysis (EDS) of HAp and magnetic oxide HAp nanocomposite before and after the lead and cobalt ions adsorption is shown in Figure 5 and Figure 6. A peak of lead ion and also cobalt ion adsorption illustrates the adsorption of the heavy metal ions.
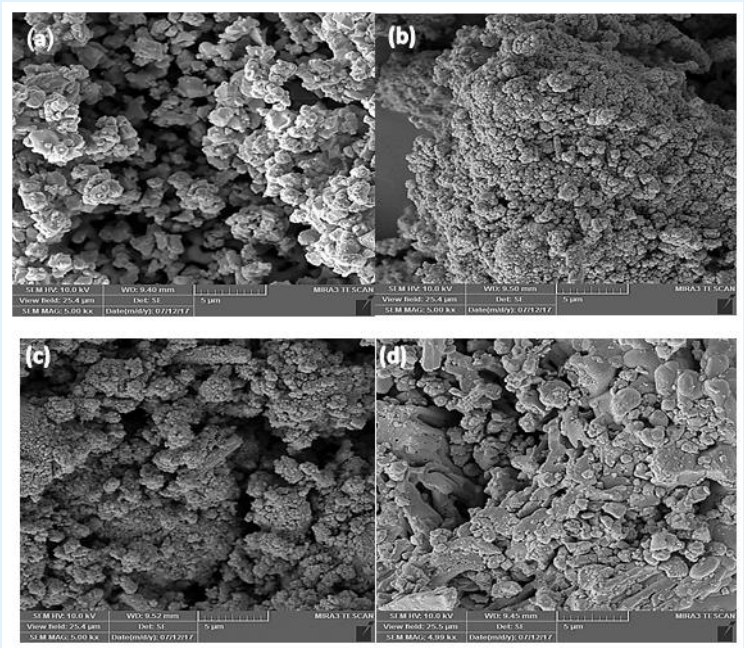

Figure 3: SEM images of the surface of (a) hydroxyapatite, (b) hydroxyapatite $/ \mathrm{Fe}_{3} \mathrm{O}_{4}$ nanocomposite, (c) hydroxyapatite after adsorption of lead ions (d) hydroxyapatite $/ \mathrm{Fe}_{3} \mathrm{O}_{4}$ composite after adsorption of lead ion.

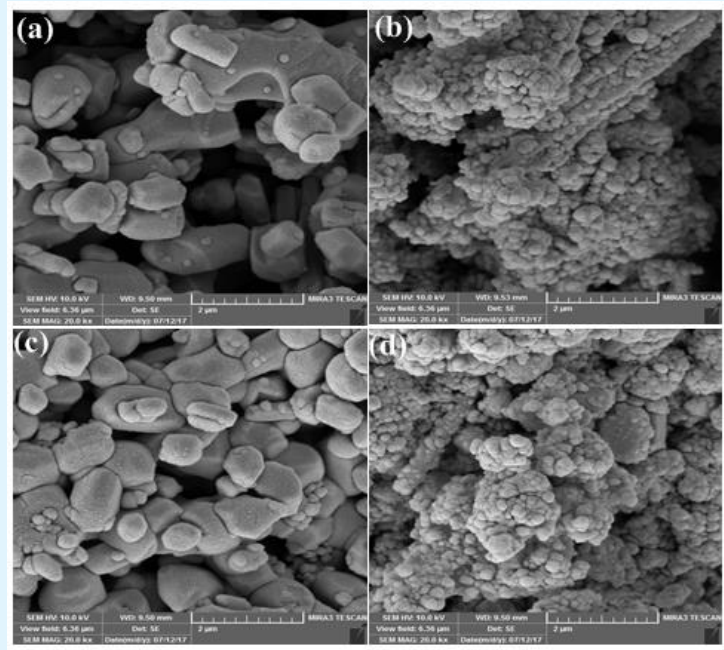

Figure 4: SEM images of the surface of (a) hydroxyapatite, (b) hydroxyapatite $/ \mathrm{Fe}_{3} \mathrm{O}_{4}$ nanocomposite, (c) hydroxyapatite after adsorption of cobalt ions (d) hydroxyapatite $/ \mathrm{Fe}_{3} \mathrm{O}_{4}$ nanocomposite after adsorption of cobalt ions. 


\section{Nanomedicine \& Nanotechnology Open Access}
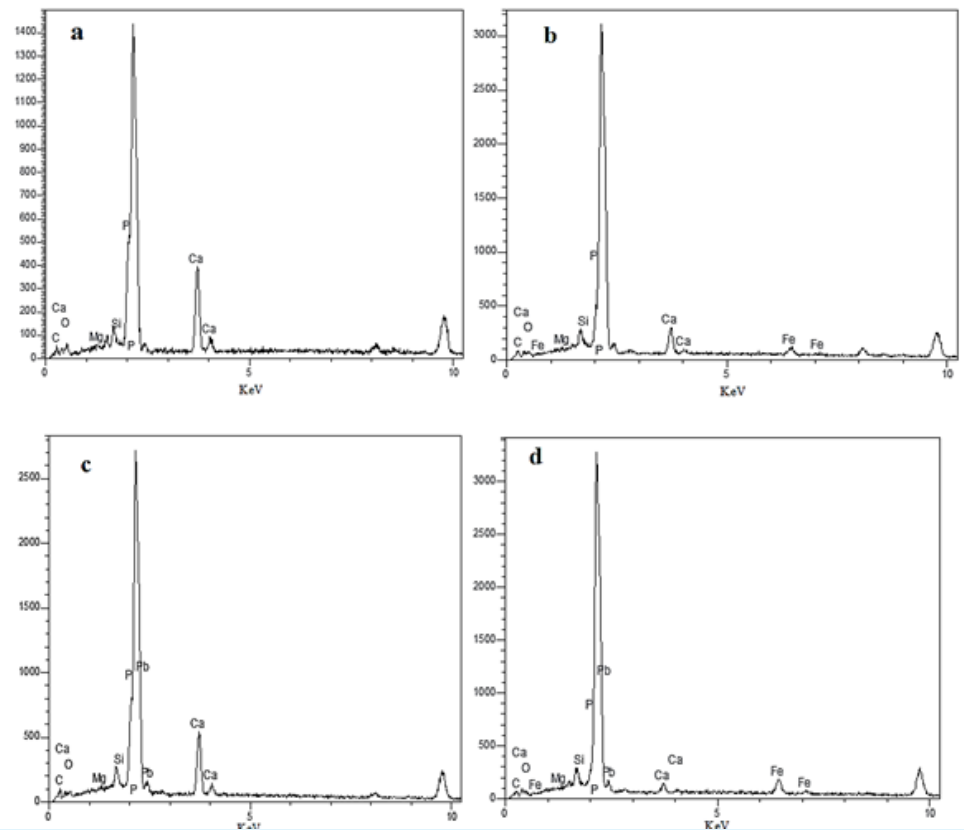

Figure 5: Elemental analysis of :(a) Hydroxyapatite, (b) Hydroxyapatite $/ \mathrm{Fe}_{3} \mathrm{O}_{4}$, (c) Hydroxyapatite after adsorption of lead ion and (d) Hydroxyapatite $/ \mathrm{Fe}_{3} \mathrm{O}_{4}$ after adsorption of lead ion.
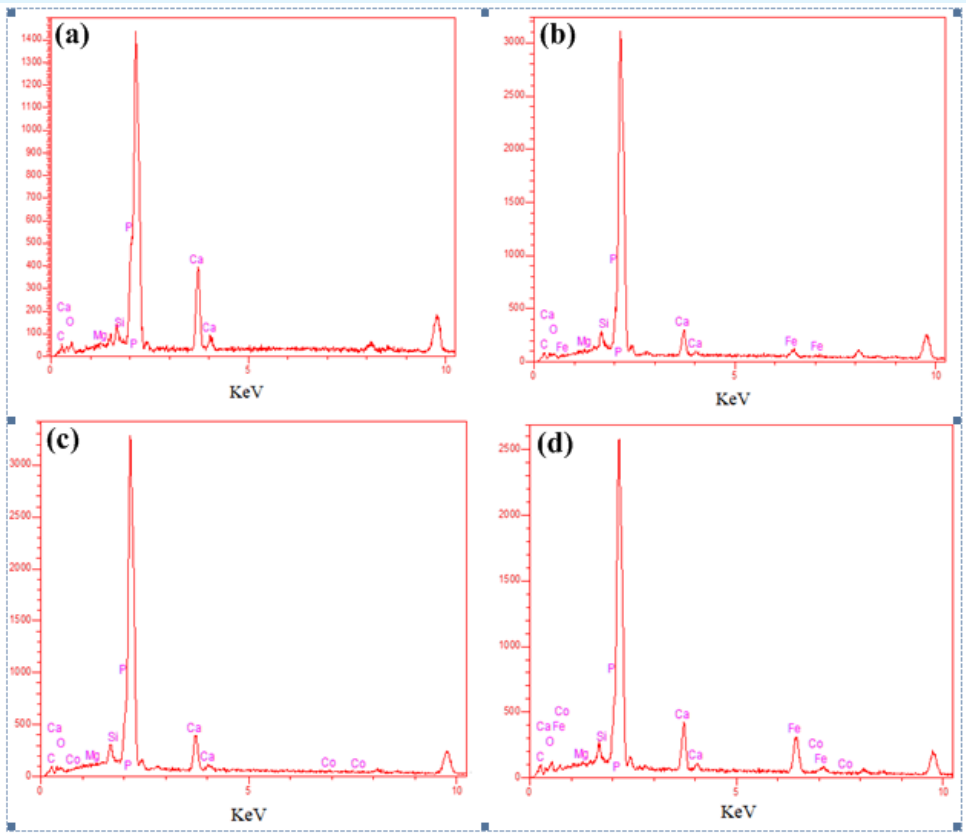

Figure 6: Elemental analysis of :(a) Hydroxyapatite, (b) Hydroxyapatite $/ \mathrm{Fe}_{3} \mathrm{O}_{4}$, (c) Hydroxyapatite after adsorption of cobalt ion and (d) Hydroxyapatite $/ \mathrm{Fe}_{3} \mathrm{O}_{4}$ after adsorption of cobalt ion. 


\section{Nanomedicine \& Nanotechnology Open Access}

\section{Effect of PH}

The initial $\mathrm{pH}$ is an important factor in the surface adsorption of the metal ions because the $\mathrm{pH}$ value is effective on the metallic ion solubility, adsorptionionization degree, and development of opposite ions in functional groups [24,25]. Also, initial $\mathrm{pH}$ of the solution is effective in changing adsorption surface charge and the degree of ionization of the adsorbing metal ions during the adsorption process. Figure 7 presents the primary $\mathrm{pH}$ effect on the lead and cobalt ions adsorption efficiency using $\mathrm{HAp}$ and magnetic $\mathrm{HAp} / \mathrm{Fe}_{3} \mathrm{O}_{4}$ composite. Other parameters including the adsorbent dose, the initial concentration of a lead ion, temperature, contact time, and mixing speed were fixed at $1 \mathrm{~g} / \mathrm{L}, 10 \mathrm{mg} / \mathrm{L}, 25^{\circ} \mathrm{C}, 40$ min, and $400 \mathrm{rpm}$, respectively. The results show that by increasing the initial $\mathrm{pH}$ from 2 to 6 , the lead adsorption efficiency increased with using both types of adsorbent. Afterward, exceeding an initial $\mathrm{pH}$ of 6 , the adsorption efficiency decreased for both adsorbents. Therefore, the initial $\mathrm{pH}$ value of 6 was reported the optimum $\mathrm{pH}$. At this $\mathrm{pH}$, the maximum lead ion adsorption efficiency using $\mathrm{HAp}$ and magnesium $\mathrm{HAp} / \mathrm{Fe}_{3} \mathrm{O}_{4}$ nanocomposite was reported to be $92.26 \%$ and $95.74 \%$, respectively. At lower $\mathrm{pH}$, lead ion adsorption is low using both of these adsorbents. Because of low $\mathrm{pH}(\mathrm{pH}<4)$, a high amount of
$\mathrm{H}+$ ions surrounded the adsorbent surface, leading to an enhanced competition between the lead ions and $\mathrm{H}+$ ions on active adsorbent sites [14]. As a result, the adsorption of lead ions on adsorbent active sites is prevented and the adsorption efficiency is declined. With the initial $\mathrm{pH}$ increasing, the amount of $\mathrm{H}+$ ion inside the solution decreases and the adsorbent surface changes negatively, leading to an increase in the adsorption of metal ions by adsorbents. At higher $\mathrm{pH}$ values $(>6)$, the percentage of metal ion adsorption decreases again, because metal ion can form complex and precipitation with the hydroxide in the solution [24]. Therefore, to remove lead ion from aqueous solution using both types of adsorbents, the initial $\mathrm{pH}$ value of 6 was reported as an optimal amount.

Also, for the cobalt ion, the maximum adsorption efficiency was approximately the same. The cobalt ion maximum adsorption was $90.48 \%$ and 94.72 for the hydroxyapatite and magnetic hydroxyapatite respectively and this maximum was about the $\mathrm{pH}$ of 6 . After the $\mathrm{pH}$ exceeded the 6 value, the adsorption efficiency began to decrease which can be attributed to the interaction of the cobalt ion and $\mathrm{OH}$ - ions. This interaction decreases the amount of the free cobalt ions and leads to the decrease in the efficiency of the cobalt ion adsorption.
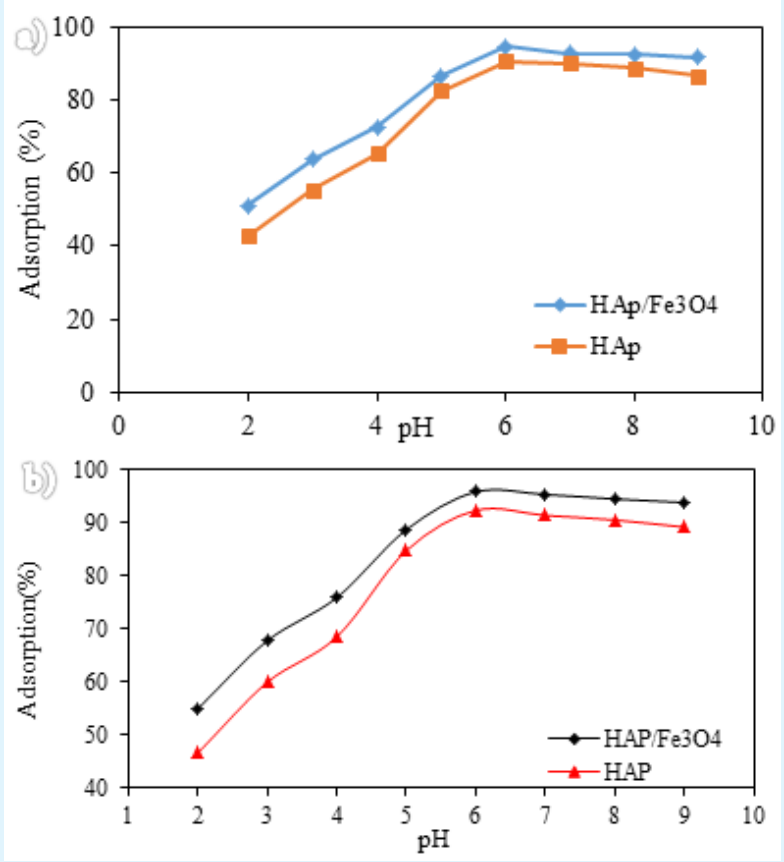

Figure 7: Effect of $\mathrm{pH}$ on adsorption efficiency: a)lead ion, b)cobalt ion)absorbent dose of $1 \mathrm{gr} / \mathrm{l}$, initial concentration of lead cobalt ion $10 \mathrm{mg} / \mathrm{l}$, temperature $25^{\circ} \mathrm{C}$, contact time of $40 \mathrm{~min}$ and mixing speed of $400 \mathrm{rpm}$. 


\section{Nanomedicine \& Nanotechnology Open Access}

\section{Effects of Temperature and Contact Time}

The initial contact time and temperature are important parameters in adsorption of heavy metal ions from aqueous solutions. The temperature has an established effect on the adsorption process because adsorption capacity of the adsorbent material varies with temperature change [26]. The effect of temperature on the efficiency of removal of lead and cobalt ions (Figures 8 and 9) was investigated using $\mathrm{HAp}$ and $\mathrm{HAp} / \mathrm{Fe}_{3} \mathrm{O}_{4}$ composite for 5-120 min, adsorption concentration of $1 \mathrm{~g} / \mathrm{L}$, and the initial concentration of $10 \mathrm{mg} / \mathrm{L}$. The results show that with temperature increasing the lead and cobalt ions adsorption efficiency decreases, suggesting that the adsorbing of these ions is an exothermic process [26-28]. The efficiency decline in the adsorption process by increasing the temperature can be due to several reasons: (1) increasing the metal ions tendency to detach from the adsorbent surface and releasing into the solution phase, (2) inactivating the adsorbent surface or degrading some of the adsorbent active sites due to chain failure [29], (3) the reduction of the electrostatic force between the metal ion and the adsorbent active sites at high temperatures [30], and (4) the weakening of the force between the metal ion and active adsorbent sites [29].

The effect of contact time on lead and cobalt ions adsorption efficiency using $\mathrm{HAp}$ and $\mathrm{HAp} / \mathrm{Fe}_{3} \mathrm{O}_{4}$ nanocomposite is shown in Figures 8 and 9, respectively. According to the obtained results, the lead ion adsorption efficiency increased with increasing time; however, in the initial contact time of 5-40 $\mathrm{min}$, and after $40 \mathrm{~min}$, there was no significant change in the adsorption efficiency. It has to be noted that at the initial contact time, the adsorption rate of the metal ion was high. Besides, more than $70 \%$ of lead ion adsorption occurred at the initial time of $15 \mathrm{~min}$, which was due to the presence of active and non-saturated sites at the adsorbent level. The maximum lead adsorption using hydroxyapatite and magnetic hydroxyapatite was $93.74 \%$ and $96.67 \%$ respectively. On the other hand, the maximum adsorption for the cobalt ion reported was a little lower and was $92.49 \%$ and $95.19 \%$ for hydroxyapatite and magnetic hydroxyapatite respectively.
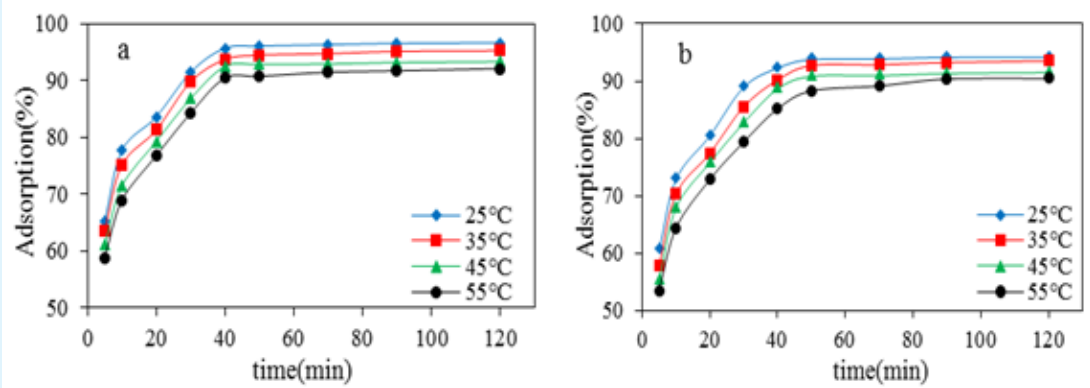

Figure 8: The effect of temperature and contact time on lead ion adsorption efficiency using: (a) hydroxyapatite $/ \mathrm{Fe}_{3} \mathrm{O}_{4}$ and (b) hydroxyapatite $(\mathrm{pH}=6$, initial concentration of $10 \mathrm{mg} / \mathrm{l}$ lead ion, absorbance dose of $1 \mathrm{gr} / \mathrm{l}$, mixing speed of $400 \mathrm{rpm}$ ).
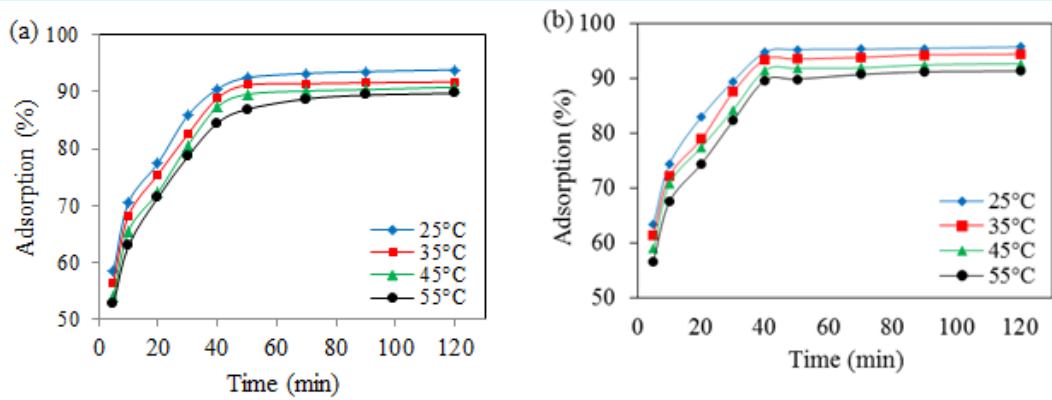

Figure 9: The effect of temperature and contact time on cobalt ion adsorption efficiency using: (a) hydroxyapatite $/ \mathrm{Fe}_{3} \mathrm{O}_{4}$ and (b) hydroxyapatite ( $\mathrm{pH}=6$, initial concentration of $10 \mathrm{mg} / \mathrm{l}$ cobalt ion, absorbance dose of $1 \mathrm{gr} / \mathrm{l}$, mixing speed of $400 \mathrm{rpm}$. 


\section{Nanomedicine \& Nanotechnology Open Access}

\section{Effect of Adsorbent Dose}

The adsorbent dose is an important parameter in adsorption of heavy metal ions from aqueous solutions because it determines the capability and adsorbent capacity in the adsorption of contaminants [30]. To investigate the effect of adsorbent dose on lead and cobalt ions adsorption efficiency, the adsorbent dose in the range of $0.25-5 \mathrm{~g} / \mathrm{L}$ was investigated (Figure 10) under the fixed condition of $\mathrm{pH}=6$, the initial concentration of lead and cobalt ions $10 \mathrm{mg} / \mathrm{L}$, temperature $25^{\circ} \mathrm{C}$, contact time of $50 \mathrm{~min}$, and stirring rate of $400 \mathrm{rpm}$. The adsorption efficiency increased from $61.27 \%$ and $68.43 \%$ to $93.75 \%$, and $96.11 \%$ for the lead and from $61.27 \%$ and $68.43 \%$ to $94.31 \%$ and $97.22 \%$ for the cobalt ion, respectively, with increasing the adsorbent dose of $\mathrm{HAp}$ and $\mathrm{HAp} / \mathrm{Fe}_{3} \mathrm{O}_{4}$ from $0.25 \mathrm{~g} / \mathrm{L}$ to $1 \mathrm{~g} / \mathrm{L}$. The results show that by increasing the adsorbent dose, the efficiency of removal of metal ion increases using these adsorbents, probably because of an increase in the number of unbound active sites due to an increase in adsorbent dose [31]. The lead and cobalt ions adsorption efficiency was increased using HAp and $\mathrm{HAp} / \mathrm{Fe}_{3} \mathrm{O}_{4}$ up to $1 \mathrm{~g} / \mathrm{L}$ at a high rate and then was almost constant with no significant change. The fixed adsorption efficiency at high concentrations of the adsorbent can be attributed to the interconnection of the active adsorbent sites or the decrease in the concentration of the metal ion in the aqueous solution for adsorption on active sites. Therefore, the amount of $1 \mathrm{~g} / \mathrm{L}$ of the adsorbent dose was determined as the optimum amount of heavy metal ions removal. Also, the reported results show that the maximum ion adsorption is higher for the cobalt ion that can be attributed to the lower density of the cobalt ion compared to the lead ion. The cobalt ion can occupy the active sites of the adsorbents easier due to the lower of the density.
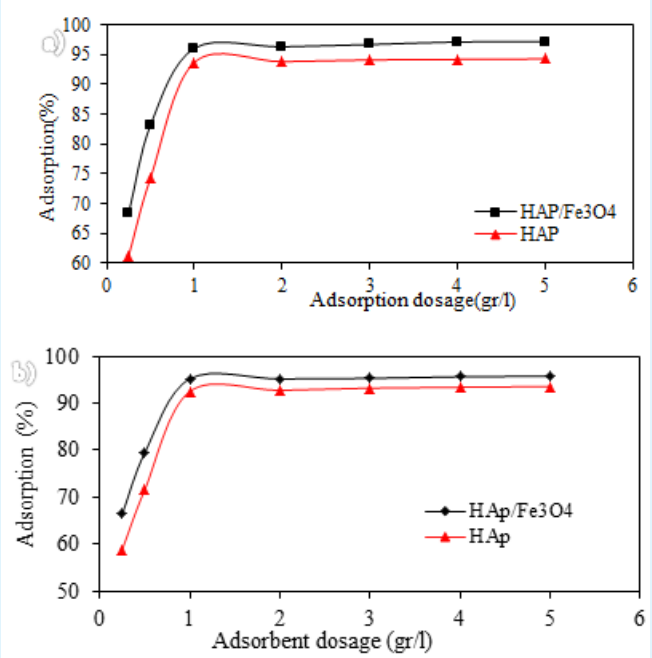

Figure 10: Effect of adsorbent dose on lead and cobalt ion adsorption efficiency using hydroxyapatite/Fe304 and hydroxyapatite a)lead, b) cobalt ( $\mathrm{pH}=6$, initial concentration of lead and cobalt ion $10 \mathrm{mg} / \mathrm{l}$, temperature $25^{\circ} \mathrm{C}$, contact time 50min, mixing speed $400 \mathrm{rpm}$ ).

\section{Isotherm Study}

Isotherm models are used to examine the behavior of solid and liquid phase during equilibrium. To describe the isotherm behaviors of the process, several isotherm models are used, with Freundlich, Langmuir, and D-R isotherm being the most important ones.

Langmuir isothermal model is a model successfully used in many homogeneous single-layer adsorption processes. The model considers adsorption by homogenous adsorbent sites. The linear form of the Langmuir model is expressed by Eq. 3:

$$
\text { C_e/q_e =C_e/q_m +1/(K_l q_m ) (3) }
$$

where Ce is the concentration of metal ion in equilibrium $(\mathrm{mg} / \mathrm{L})$, qe $(\mathrm{mg} / \mathrm{g})$ is the amount of metal ion adsorbed in equilibrium per gram of adsorbent, and qmax and kL are Langmuir model constants representing adsorption capacity $(\mathrm{mg} / \mathrm{g})$ and adsorption energy (L/g), respectively. These constants are obtained by measuring 


\section{Nanomedicine \& Nanotechnology Open Access}

the slope and y-intercept of the linear equation of Ce/qe as a function of Ce. Another important and effective parameter that characterizes the properties and properties of the Langmuir equation is a dimensionless factor called isolation factor (RL). The RL represents the state of adsorption isotherm model. For values $R L>1$, $\mathrm{RL}=0, \mathrm{RL}=1$, and $0<\mathrm{RL}<1$, the process is undesirable, irreversible, linear, and desirable, respectively [32]. The RL is determined using Eq. 4:

$$
\text { R_L }=1 /\left(1+K \_L ~ C \_0 ~\right) ~(4)
$$

where $\mathrm{C} 0(\mathrm{mg} / \mathrm{L})$ is the initial concentration of the ion in aqueous solution.

The Freundlich isotherm is an experimental model capable of describing the adsorption of organic and inorganic compounds by a variety of adsorbents. This model is used for non-ideal adsorption within nonhomogeneous surfaces. The linear form of this model is Eq. 5 [33]:

$$
\text { Lnq_e=LnK_f }+1 / \text { n LnC_e (5) }
$$

where qe $(\mathrm{mg} / \mathrm{g})$ is the equilibrium adsorption capacity, Ce $(\mathrm{mg} / \mathrm{L})$ is the equilibrium concentration of the metal ion in solution, $\mathrm{Kf}$ and $\mathrm{n}$ are the adsorption process constants that represent respectively the adsorption capacity, force, and the adsorption power, and are determined from the slope and Intercept of Freundlich linear equation.

The $\mathrm{D}-\mathrm{R}$ isotherm model is another isotherm model used in previous studies [34]. As a semi-experimental model, D-R assumes that adsorption occurs within the multilayer levels resulting from Van der Waals forces. This model is also used to detect the type of physical and chemical adsorption process. The linear form of this model is expressed by Eq. 6 :

$$
\text { lnq_e}=\operatorname{lnq} q_{-}-\beta \varepsilon^{\wedge} 2(6)
$$

where $\beta\left(\mathrm{mol}^{2} / \mathrm{J} 2\right)$ and $\mathrm{qm}(\mathrm{mg} / \mathrm{g})$ are the constants of the $\mathrm{D}-\mathrm{R}$ model and $\varepsilon$ is the Polanyi potential determined from the equation $\varepsilon=\mathrm{RT} \ln (1+1 / \mathrm{Ce})$. $\mathrm{R}$ is the constant of the gases $(8.314 \mathrm{~J} / \mathrm{mol} . \mathrm{K})$ and $\mathrm{T}$ is the absolute temperature (K). To determine the constants of the D-R isotherm model, the diagram of lnqe versus $\varepsilon 2$ was used. Moreover, $\beta$ and $\mathrm{qm}$ were obtained from slope and y-intercept, respectively.

where $\beta$ represents the mean free energy of the adsorption (E), which is determined by Eq. 7:

$$
\mathrm{E}=1 / \sqrt{2} \beta(7)
$$

The average free energy of the adsorption determines the type of adsorption process. If the average free energy of adsorption is between 8 and $16 \mathrm{KJ} / \mathrm{mol}$, the adsorption process is a changing ion type. If the mean free energy of adsorption is less than $8 \mathrm{KJ} / \mathrm{mol}$, it shows that the mechanism of adsorption is physical [34].

The linear relationship and parameters of Langmuir, Freundlich and D-R isotherm models for the lead and cobalt ions are shown in Figures 11 and Table 1 and 2, respectively. The determined correlation coefficient (R2) using the Freundlich and Langmuir isotherm model (R2>0.94) for the lead and cobalt ions adsorption has approximately the same values for both of the adsorbents, suggesting that the ions adsorption process followed by using the adsorbents from both the Freundlich and Langmuir isotherm models, and homogeneous and heterogeneous levels have played a role in the process of elimination [35]. The value of the parameters $\mathrm{n}$ and $\mathrm{Kf}$ of the Freundlich isotherm model indicate that the ion adsorption process is physical and desirable and $\mathrm{HAp} / \mathrm{Fe}_{3} \mathrm{O}_{4}$ magnetic nanocomposite compared to $\mathrm{HAp}$ adsorbs more lead and cobalt ions from aqueous solution. The maximum adsorption capacity was determined using the Langmuir equation; i.e., $105.263 \mathrm{mg} / \mathrm{g}$ and 109.89 $\mathrm{mg} / \mathrm{g}$ for lead and $102.04 \mathrm{mg} / \mathrm{g}$ and $107.52 \mathrm{mg} / \mathrm{g}$ for cobalt using $\mathrm{HAp}$ and $\mathrm{HAp} / \mathrm{Fe}_{3} \mathrm{O}_{4}$ nanocomposites, respectively. Different RL values were less than 1 for lead and cobalt ions adsorption using $\mathrm{HAp}$ and $\mathrm{HAp} / \mathrm{Fe}_{3} \mathrm{O}_{4}$ nanocomposite, showing that the ion adsorption using the adsorbents is a convenient and desirable process. The free energy was determined to be $1.261 \mathrm{KJ} / \mathrm{mol}$ and $1.666 \mathrm{KJ} / \mathrm{mol}$ using the $\mathrm{D}-\mathrm{R}$ model for the adsorption of lead and $1.11 \mathrm{KJ} / \mathrm{mol}$ and $1.49 \mathrm{KJ} / \mathrm{mol}$ for cobalt ions using $\mathrm{HAp}$ and $\mathrm{HAp} / \mathrm{Fe}_{3} \mathrm{O}_{4}$ nanocomposite, respectively. Considering the amount of determined free energy, it was concluded that the process of adsorption of lead and cobalt metal ions using the adsorbents is physical because the calculated $\mathrm{E}$ value is less than $8 \mathrm{KJ} / \mathrm{mol}$ for both the metal ions. 


\section{Nanomedicine \& Nanotechnology Open Access}
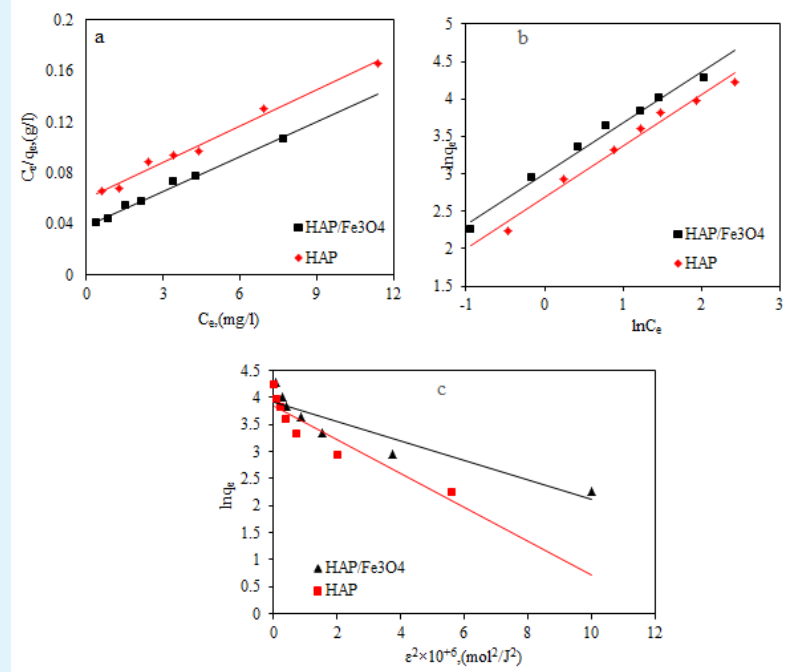

Figure 11: The linear relationship of isothermic models (a) Langmuir, (b) Freundlich, and (c) the D-R model for the adsorption of lead and cobalt ions.

\begin{tabular}{|c|c|c|c|}
\hline Models & Parameters & HAP/Fe $\mathrm{O}_{4}$ & HAP \\
\hline Langmuir & $\mathrm{q}_{\mathrm{m}}(\mathrm{mg} / \mathrm{g})$ & 109.89 & 105.263 \\
\hline \multirow{2}{*}{$\mathrm{C}_{\mathrm{e}} / \mathrm{q}_{\mathrm{e}}=\mathrm{C}_{\mathrm{e}} / \mathrm{q}_{\mathrm{m}}+1 / \mathrm{K}_{\mathrm{l}} \mathrm{q}_{\mathrm{m}}$} & $\mathrm{K}_{\mathrm{L}}(\mathrm{L} / \mathrm{mg})$ & 0.237 & 0.158 \\
\hline & $\mathrm{R}^{2}$ & 0.991 & 0.9868 \\
\cline { 2 - 4 } & $\mathrm{R}_{\mathrm{L}}$ & $0.051-0.296$ & $0.0733-0.387$ \\
\hline Freundlich & $\mathrm{n}$ & 1.479 & 1.466 \\
\hline \multirow{2}{*}{$\operatorname{lnq}_{\mathrm{e}}=\ln \mathrm{K}_{\mathrm{f}}+1 / \mathrm{n} \operatorname{lnC} \mathrm{e}_{\mathrm{e}}$} & $\mathrm{K}_{\mathrm{f}}\left(\mathrm{mg} / \mathrm{g}(\mathrm{L} / \mathrm{mg})^{1 / \mathrm{n}}\right)$ & 20.263 & 14.69 \\
\hline DubininRadushkevich & $\mathrm{R}^{2}$ & 0.9866 & 0.9794 \\
\hline$(\mathrm{D}-\mathrm{R})$ & $\mathrm{E}(\mathrm{KJ} / \mathrm{mol})$ & 1.666 & 1.261 \\
\hline \multirow{2}{*}{$\ln q_{\mathrm{e}}=\ln \mathrm{q}_{\mathrm{m}}-\beta \varepsilon^{2}$} & $\mathrm{q}_{\mathrm{m}}(\mathrm{mg} / \mathrm{g})$ & 49.973 & 47.275 \\
\cline { 2 - 4 } & $\beta \times 10^{6}\left(\mathrm{~mol}{ }^{2} / \mathrm{J}^{2}\right)$ & 0.1801 & 0.3143 \\
\cline { 2 - 4 } & $\mathrm{R}^{2}$ & 0.8693 & 0.8611 \\
\hline
\end{tabular}

Table 1: Isotermic Parameters Determined for Lead-ion Adsorption Processes Using Hydroxyapatite and Hydroxyapatite $/ \mathrm{Fe}_{3} \mathrm{O}_{4}$

\begin{tabular}{|c|c|c|c|}
\hline Models & Parameters & $\mathrm{HAP} / \mathrm{Fe}_{3} \mathrm{O}_{4}$ & $\mathrm{HAP}$ \\
\hline \multirow{2}{*}{ Langmuir } & $\mathrm{q}_{\mathrm{m}}(\mathrm{mg} / \mathrm{g})$ & 107.526 & 102.04 \\
\cline { 2 - 4 } & $\mathrm{K}_{\mathrm{L}}(\mathrm{L} / \mathrm{mg})$ & 0.185 & 0.1406 \\
\hline $\mathrm{y}=0.0093 \mathrm{x}+0.0503\left(\mathrm{HAp} / \mathrm{Fe}_{3} \mathrm{O}_{4}\right)$ & $\mathrm{R}^{2}$ & 0.9823 & 0.9954 \\
\hline $\mathrm{y}=0.0098 \mathrm{x}+0.0697(\mathrm{HAp})$ & $\mathrm{R}_{\mathrm{L}}$ & $0.0633-0.351$ & $0.0816-0.415$ \\
\hline Freundlich & $\mathrm{n}$ & 1.494 & 1.465 \\
\hline $\mathrm{y}=0.6693 \mathrm{x}+2.8244\left(\mathrm{HAp} / \mathrm{Fe}_{3} \mathrm{O}_{4}\right)$ & $\mathrm{K}_{\mathrm{f}}\left(\mathrm{mg} / \mathrm{g}(\mathrm{L} / \mathrm{mg})^{1 / \mathrm{n}}\right)$ & 16.85 & 13.144 \\
\hline $\mathrm{y}=0.6823 \mathrm{x}+2.576(\mathrm{HAp})$ & $\mathrm{R}^{2}$ & 0.9854 & 0.9738 \\
\hline Dubinin-Radushkevich $(\mathrm{D}-\mathrm{R})$ & $\mathrm{E}(\mathrm{KJ} / \mathrm{moL})$ & 1.492 & 1.115 \\
\hline $\mathrm{y}=-0.2245 \mathrm{x}+3.8497\left(\mathrm{HAp} / \mathrm{Fe}_{3} \mathrm{O}_{4}\right)$ & $\mathrm{q}_{\mathrm{m}}(\mathrm{mg} / \mathrm{g})$ & 46.978 & 46.768 \\
\hline $\mathrm{y}=-0.4023 \mathrm{x}+3.8452(\mathrm{HAp})$ & $\beta \mathrm{x} 10^{-6}\left(\mathrm{~mol}{ }^{2} / \mathrm{J}^{2}\right)$ & 0.2245 & 0.4023 \\
\hline
\end{tabular}

Table 2: Isotermic Parameters Determined for cobalt-ion Adsorption Processes Using Hydroxyapatite and Hydroxyapatite $/ \mathrm{Fe}_{3} \mathrm{O}_{4}$ 


\section{Nanomedicine \& Nanotechnology Open Access}

\section{Study of Thermodynamics}

In this study, to evaluate the process behavior, we investigated thermodynamic parameters such as enthalpy $(\Delta \mathrm{H} 0)$, entropy $(\Delta \mathrm{S} 0)$, and Gibbs free energy $(\Delta \mathrm{G} 0)$. The thermodynamic parameters are determined using the Eq. 8:

$$
\Delta \mathrm{G}^{\circ}=-\mathrm{RT}_{\ln } \mathrm{L}_{-}(\mathrm{D})(8)
$$

where $\Delta \mathrm{GO}$ is the free energy of Gibbs, $\mathrm{R}$ is the universal gas constant $(8.314 \mathrm{~J} / \mathrm{mol} . \mathrm{K}), \mathrm{T}$ is absolute temperature $(\mathrm{K})$, and $\mathrm{kD}$ is equilibrium constant. The constant value of the adsorption equilibrium is determined by Eq. 9:

$$
\text { k_D=q_e/C_e (9) }
$$

where qe is the amount of metal ion adsorbed on the surface of the adsorbents at the time of equilibrium $(\mathrm{mg} / \mathrm{g})$ and Ce is the amount of metal ion remaining in solution during the equilibrium.

In order to determine the thermodynamic parameters of enthalpy $(\Delta \mathrm{H} 0)$ and entropy $(\Delta \mathrm{S} 0)$, Eq. 10 was used:

$$
\operatorname{lnk}=\left(-\Delta \mathrm{G}^{\circ}\right) / \mathrm{RT}=\left(-\Delta \mathrm{H}^{\circ}\right) / \mathrm{RT}+\left(\Delta \mathrm{S}^{\circ}\right) / \mathrm{R}(10)
$$

The values of $\Delta \mathrm{H} 0$ and $\Delta \mathrm{S} 0$ are determined from the slope and intercept of the LnkD curve vs. 1/T (Figure 12), and the values are shown in Tables 3 and 4. Gibbs free energy calculated for the lead and cobalt ions adsorbents was negative, which indicates that it is thermodynamically optimal and spontaneous. Also, the value of $\Delta \mathrm{HO}$ was negative, suggesting that the interactions between adsorbents and the ions are exothermal. It also shows that the process of adsorption of the heavy metal ions using the adsorbents is physical because $\Delta \mathrm{HO}$ is less than $40 \mathrm{KJ} / \mathrm{mol}$. The amount of $\Delta \mathrm{SO}$ was negative for the lead and cobalt ions adsorption process, showing the reduced random collisions of the ions in the solid (adsorbent) and aqueous solution during the adsorption [36].
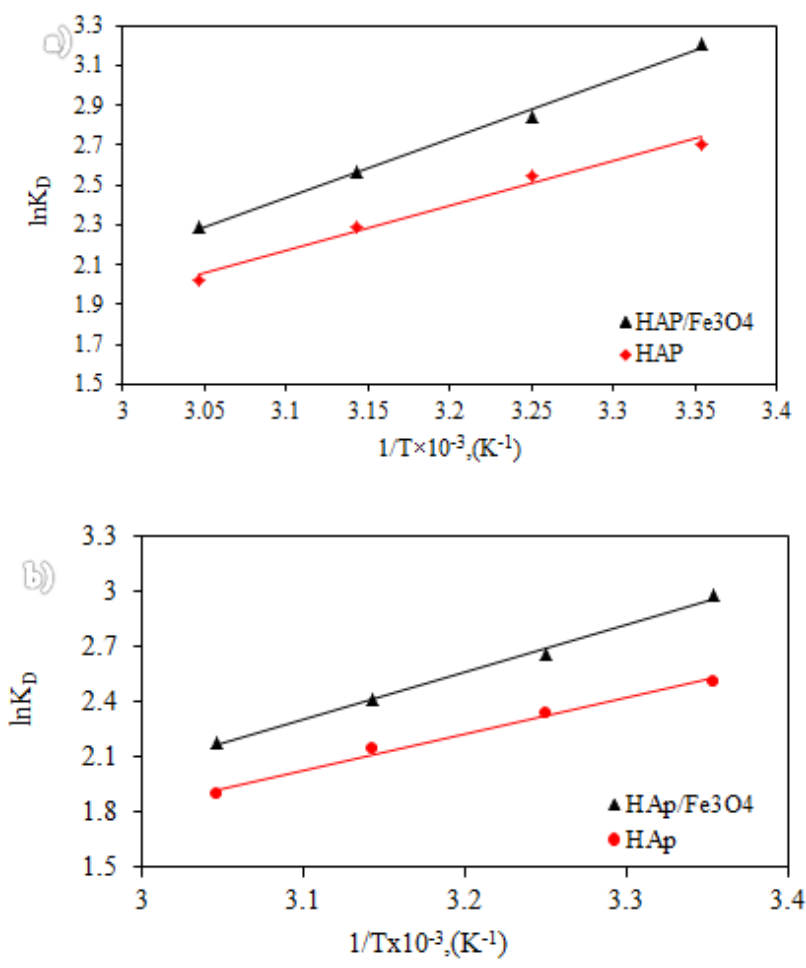

Figure 12: Plot of of lnkp versus 1/T for adsorption of a) $\mathrm{Pb}$ onto the $\mathrm{HAP} / \mathrm{Fe}_{3} \mathrm{O}_{4}$ and $\mathrm{HAP}$. b) Co onto the

\begin{tabular}{|c|c|c|c|c|}
\hline Adsorbent & $\mathrm{T}(\mathrm{K})$ & $\Delta \mathrm{G}^{\circ}(\mathrm{KJ} / \mathrm{moL})$ & $\Delta \mathrm{H}^{\circ}(\mathrm{KJ} / \mathrm{moL})$ & $\Delta \mathrm{S}^{\circ}(\mathrm{J} / \mathrm{mol} . \mathrm{K})$ \\
\hline \multirow{4}{*}{$\mathrm{HAP} / \mathrm{Fe}_{3} \mathrm{O}_{4}$} & 298.15 & -7.949 & \multirow{4}{*}{-24.559} & \multirow{4}{*}{-55.884} \\
\hline & 308.15 & -7.29 & & \\
\hline & 318.15 & -6.789 & & \\
\hline & 328.15 & -6.242 & & \\
\hline \multirow{4}{*}{ HAP } & 298.15 & -6.712 & \multirow{4}{*}{-18.687} & \multirow{4}{*}{-39.899} \\
\hline & 308.15 & -6.514 & & \\
\hline & 318.15 & -6.062 & & \\
\hline & 328.15 & -5.511 & & \\
\hline
\end{tabular}
$\mathrm{HAP} / \mathrm{Fe}_{3} \mathrm{O}_{4}$ and HAP. (CO: $10 \mathrm{mg} / \mathrm{L}$; adsorbent dose: gr/l; time: $50 \mathrm{~min}$; $\mathrm{pH}: 6$ ).

Table 3: Thermodynamic parameters determined for the lead ion adsorption process using $\mathrm{HAP} / \mathrm{Fe}_{3} \mathrm{O}_{4}$ and $\mathrm{HAP}$ adsorbents. 
Nanomedicine \& Nanotechnology Open Access

\begin{tabular}{|c|c|c|c|c|}
\hline Adsorbent & $\mathrm{T}(\mathrm{K})$ & $\Delta \mathrm{G}^{\circ}(\mathrm{KJ} / \mathrm{moL})$ & \multirow{2}{*}{$\Delta \mathrm{H}^{\circ}(\mathrm{KJ} / \mathrm{moL})$} & $\Delta \mathrm{S}^{\circ}(\mathrm{J} / \mathrm{moL} . \mathrm{K})$ \\
\hline \multirow{4}{*}{$\mathrm{HAP} / \mathrm{Fe}_{3} \mathrm{O}_{4}$} & 298.15 & -7.399 & \multirow{3}{*}{-21.603} & -47.828 \\
\cline { 2 - 3 } & 308.15 & -6.809 & & \\
\cline { 2 - 3 } & 318.15 & -6.385 & & \\
\cline { 2 - 3 } & 328.15 & -5.937 & & \\
\hline \multirow{3}{*}{$\mathrm{HAP}$} & 298.15 & -6.221 & -16.419 & -34.032 \\
\cline { 2 - 3 } & 308.15 & -5.992 & \\
\cline { 2 - 3 } & 318.15 & -5.684 & & \\
\cline { 2 - 3 } & 328.15 & -5.17 & & \\
\hline
\end{tabular}

Table 4: Thermodynamic parameters determined for the cobalt ion adsorption process using $\mathrm{HAP} / \mathrm{Fe}_{3} \mathrm{O}_{4}$ and $\mathrm{HAP}$ adsorbents.

\section{Kinetic Study}

Adsorption kinetics is used to determine the mechanism of controlling adsorption processes such as surface adsorption, chemical reaction, and penetration mechanisms. Several models have been used in previous works for studying the adsorption kinetics. In the present work, pseudo-first-order kinetic models and pseudosecond-order kinetic models were used to investigate the kinetic behavior of lead and cobalt ions adsorption using $\mathrm{HAp}$ and magnetic-magnetic composite $\mathrm{HAp} / \mathrm{Fe}_{3} \mathrm{O}_{4}$.

The linear equations of pseudo-first-order and secondorder kinetic models are shown by Eqs. 11 and 12, respectively

$$
\begin{gathered}
\text { Ln(q_e-q_t })=\operatorname{lnq} q_{-} e-k_{-} 1 t(11) \\
t / q_{-} t=\left(1 /\left(K_{-} 2 q_{-} e^{\wedge} 2\right)\right)+t / q_{-} e(12)
\end{gathered}
$$

where qe is the amount of ion adsorbed in equilibrium $(\mathrm{mg} / \mathrm{g})$, qt is the amount of ion adsorbed (mg/g) per gram of adsorbent at any time, and $\mathrm{k} 1$ is the constant adsorption of the pseudo-first-order kinetics (1/min), and $\mathrm{K} 2$ is the second-order kinetic equilibrium constant (g.mg-1.g-1). The kinetic parameters for pseudo-first and second kinetic models for adsorption of lead and cobalt ions using the adsorbents at temperatures of $25-55^{\circ} \mathrm{C}$ are respectively determined by plotting the linear relation between $\ln (\mathrm{qe}-\mathrm{q} t)$ and $t / \mathrm{qt}$ vs. $t$ that are shown in Figures $13-16$.
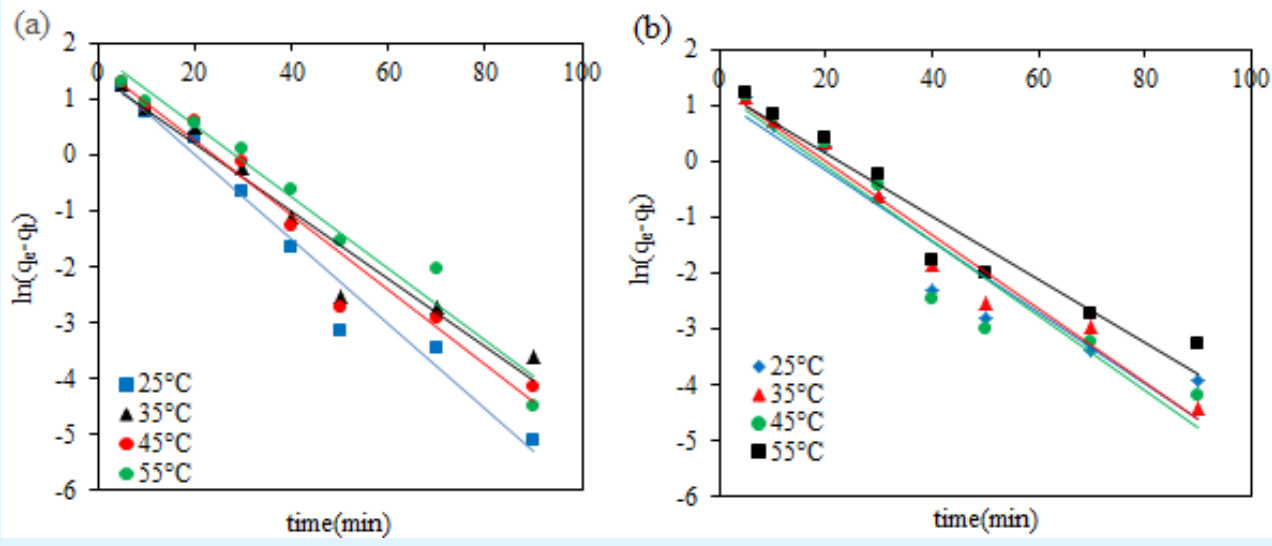

Figure 13: Linear relationship of quasi-first-order kinetics model for the process of adsorption of lead metal ions by using (a) hydroxyapatite (b) hydroxyapatite $/ \mathrm{Fe}_{3} \mathrm{O}_{4}$ adsorbents. 


\section{Nanomedicine \& Nanotechnology Open Access}
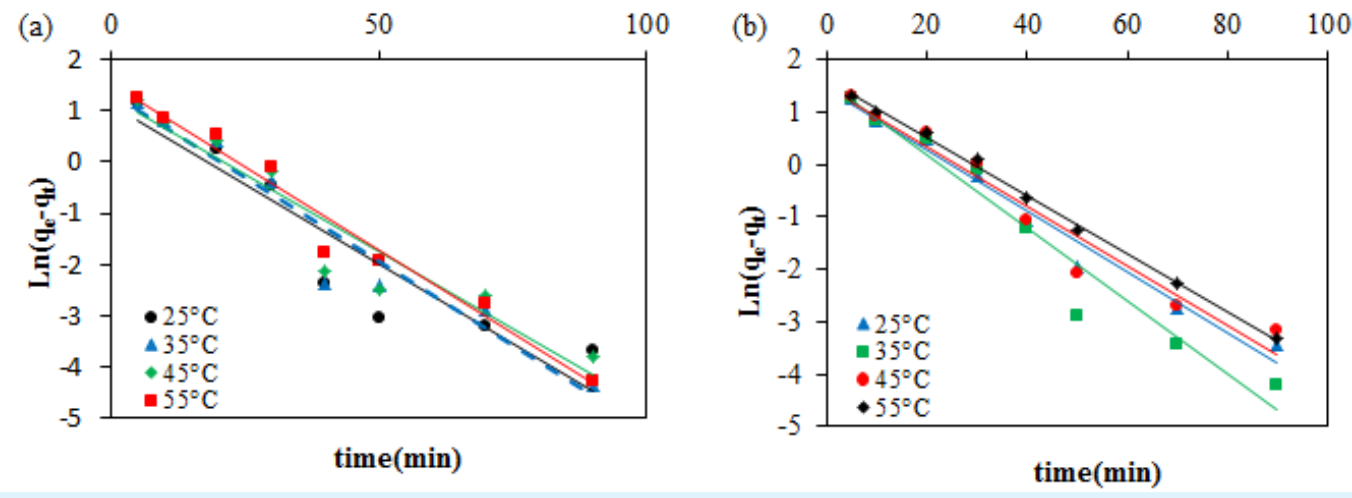

Figure 14: Linear relationship of quasi-first-order kinetics model for the process of adsorption of cobalt metal ions by using (a) hydroxyapatite (b) hydroxyapatite $/ \mathrm{Fe}_{3} \mathrm{O}_{4}$ adsorbents.
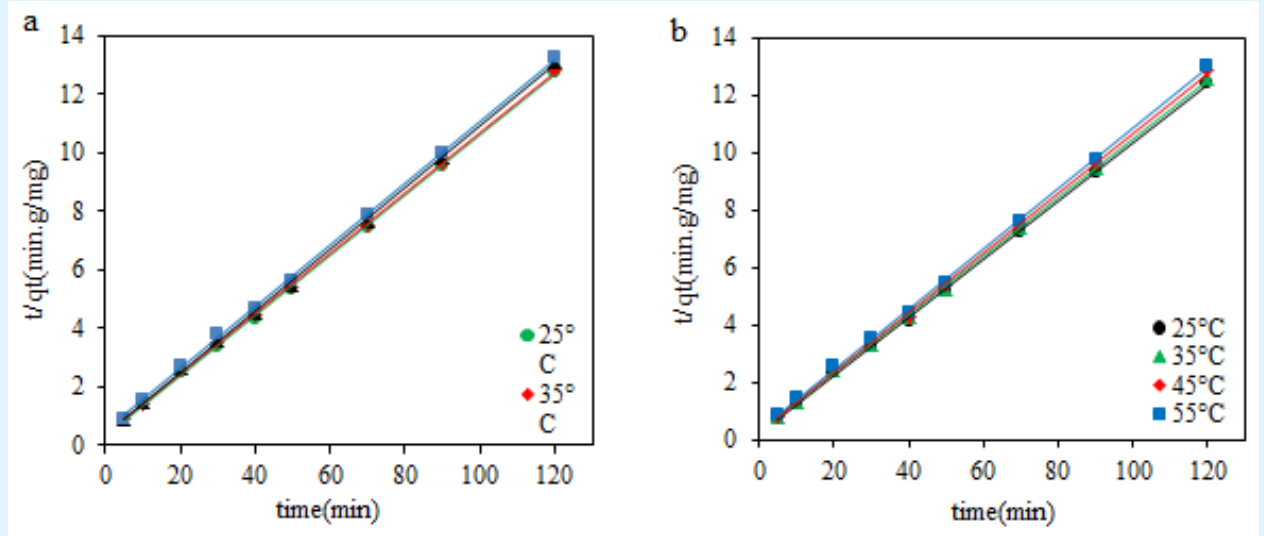

Figure 15: The linear relationship between pseudo second order kinetic models for the process of adsorption of lead metal ions by adsorbents of (a) hydroxyapatite (b) hydroxyapatite $/ \mathrm{Fe}_{3} \mathrm{O}_{4}$.
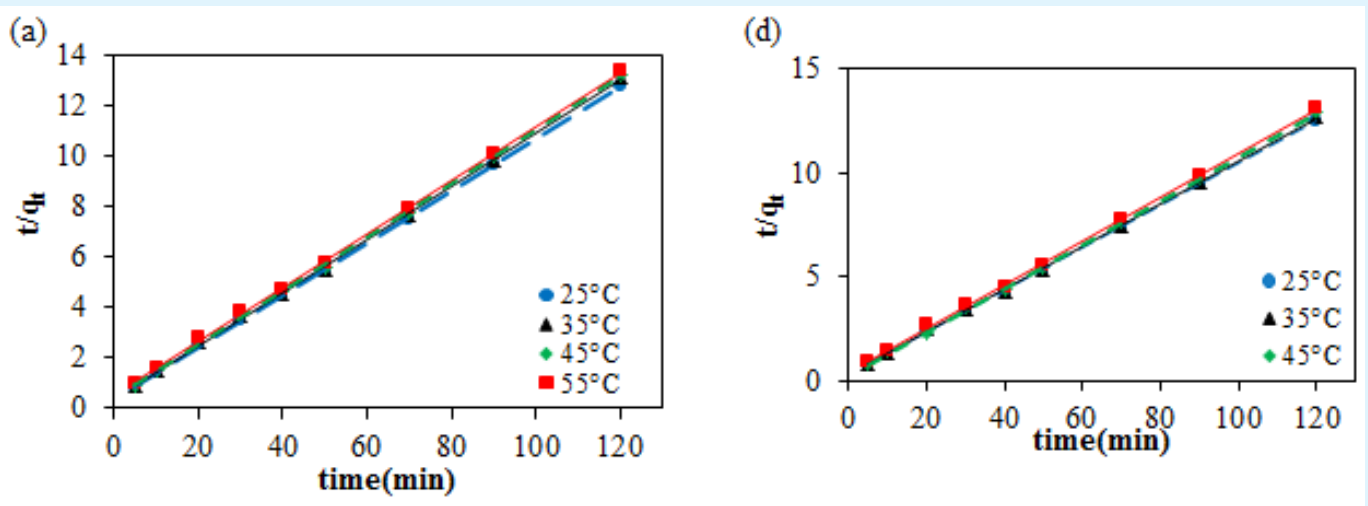

Figure 16: The linear relationship between pseudo second order kinetic models for the process of adsorption of cobalt metal ions by adsorbents of (a) hydroxyapatite (b) hydroxyapatite/ $/ \mathrm{Fe}_{3} \mathrm{O}_{4}$ 


\section{Nanomedicine \& Nanotechnology Open Access}

The parameters and constants determined using the kinetic models are shown in Tables 5 and 6 . The results show that pseudo-second-order kinetic models have a higher coefficient of determination (R2) compared to the first-order kinetic models in different temperatures, suggesting that the lead ion adsorption better follows the pseudo-second-order kinetic model. It is also worth noting that the changes in the adsorption capacity (qe.cal) are not consistent with the use of first-order kinetic models with temperature changes, and are less than the adsorption capacity determined by the adsorption process (qe. (Exp)). Accordingly, it can be argued that the first-order kinetic model is not well suited for describing the kinetic behavior of the lead ion adsorption process using the desired adsorbents [24]. Meanwhile, these changes are known in a pseudo-second-order kinetic model, and the amount of adsorption capacity is reduced with increasing temperature. The results obtained for the cobalt are given in table showing that this ion has the same behavior as lead.

\begin{tabular}{|c|c|c|c|c|c|c|c|}
\hline \multirow{2}{*}{ Temperature $(\mathrm{K})$} & \multirow{2}{*}{$\mathrm{q}_{\text {e.exp }}(\mathrm{mg} / \mathrm{g})$} & \multicolumn{3}{c|}{ Pseudo-first-order } & \multicolumn{3}{c|}{ Pseudo-second-order } \\
\cline { 2 - 8 } & $\mathrm{K}_{1}(1 / \mathrm{min})$ & $\mathrm{q}_{\mathrm{e} 1 . \text { cal }}(\mathrm{mg} / \mathrm{g})$ & $\mathrm{R}^{2}$ & $\mathrm{~K}_{2}$ (g/mg.min) & $\mathrm{q}_{\mathrm{e} 2 \text {.cal }}(\mathrm{mg} / \mathrm{g})$ & $\mathrm{R}^{2}$ \\
\hline \multicolumn{7}{|c|}{$\mathrm{HAP}_{\mathrm{Fe}} \mathrm{O}_{4}$} \\
\hline 298.15 & 9.671 & 0.0637 & 3.085 & 0.9185 & 0.0402 & 9.93 & 0.9997 \\
\hline 308.15 & 9.529 & 0.066 & 3.732 & 0.9669 & 0.037 & 9.803 & 0.9996 \\
\hline 318.15 & 9.336 & 0.067 & 3.518 & 0.9101 & 0.0351 & 9.633 & 0.9995 \\
\hline 328.15 & 9.214 & 0.0562 & 3.54 & 0.9358 & 0.0307 & 9.532 & 0.9995 \\
\hline \multicolumn{7}{|c|}{} \\
\hline 298.15 & 9.418 & 0.0757 & 4.547 & 0.9714 & 0.0354 & 9.708 & 0.9996 \\
\hline 308.15 & 9.35 & 0.0605 & 4.157 & 0.95 & 0.0286 & 9.689 & 0.9996 \\
\hline 318.15 & 9.148 & 0.0668 & 4.845 & 0.9549 & 0.028 & 9.505 & 0.9995 \\
\hline 328.15 & 9.047 & 0.064 & 6.048 & 0.966 & 0.0228 & 9.451 & 0.9995 \\
\hline
\end{tabular}

Table 5: The kinetic parameters determined for the lead ion adsorption process using hydroxyapatite and hydroxyapatite $/ \mathrm{Fe}_{3} \mathrm{O}_{4}$ adsorbents.

\begin{tabular}{|c|c|c|c|c|c|c|c|}
\hline \multirow{2}{*}{ Temperature (K) } & \multirow{2}{*}{$\mathrm{q}_{\mathrm{e} . \exp }(\mathrm{mg} / \mathrm{g})$} & \multicolumn{3}{|c|}{ Pseudo-first-order } & \multicolumn{3}{|c|}{ Pseudo-second-order } \\
\hline & & $\mathrm{K}_{1}(1 / \mathrm{min})$ & $\mathrm{q}_{\mathrm{e} 1 . \text { cal }}(\mathrm{mg} / \mathrm{g})$ & $\mathrm{R}^{2}$ & $\mathrm{~K}_{2}$ (g mg $^{-1} \mathrm{~min}^{-1}$ & $\mathrm{q}_{\mathrm{e} 2 . \text { cal }}(\mathrm{mg} / \mathrm{g})$ & $\mathrm{R}^{2}$ \\
\hline \multicolumn{8}{|c|}{$\mathrm{HAp} / \mathrm{Fe}_{3} \mathrm{O}_{4}$} \\
\hline 298.15 & 9.566 & 0.0623 & 3.08 & 0.8825 & 0.0373 & 9.842 & 0.9996 \\
\hline 308.15 & 9.434 & 0.066 & 3.883 & 0.9352 & 0.0328 & 9.746 & 0.9995 \\
\hline 318.15 & 9.236 & 0.0607 & 3.634 & 0.9141 & 0.0407 & 9.505 & 0.9995 \\
\hline 328.15 & 9.127 & 0.0653 & 4.678 & 0.9697 & 0.0278 & 9.478 & 0.9993 \\
\hline \multicolumn{8}{|c|}{ HAp } \\
\hline 298.15 & 9.39 & 0.0582 & 4.21 & 0.9772 & 0.028 & 9.737 & 0.9996 \\
\hline 308.15 & 9.177 & 0.0697 & 4.903 & 0.952 & 0.0277 & 9.542 & 0.994 \\
\hline 318.15 & 9.084 & 0.057 & 4.42 & 0.9532 & 0.024 & 9.478 & 0.9992 \\
\hline 328.15 & 8.978 & 0.0553 & 5.041 & 0.9971 & 0.022 & 9.389 & 0.9995 \\
\hline
\end{tabular}

Table 6: The kinetic parameters determined for the cobalt ion adsorption process using hydroxyapatite and hydroxyapatite $/ \mathrm{Fe}_{3} \mathrm{O}_{4}$ adsorbents.

\section{Conclusion}

In summary, $\mathrm{HAp}$ and $\mathrm{HAp} / \mathrm{Fe}_{3} \mathrm{O}_{4}$ magnetic nanocomposites were synthesized and used as an adsorbent for the effective adsorption of lead and cobalt ions. The processing parameters were studied and found that the adsorption concentration and the contact time increased with an increase in adsorption level. FTIR results confirmed the presence of functional groups such as hydroxyl, phosphate, and carbonyl groups, which are effective for the recovery and adsorption of metal ions. The first-order and second-order kinetic models were used to study the kinetic behavior of the process and found that pseudo-second-order kinetic models have the potential to describe the kinetic behavior of the adsorption process. Thermodynamic parameters such as enthalpy $(\Delta \mathrm{H} 0)$, entropy $(\Delta \mathrm{S} 0)$, and Gibbs free energy $(\Delta G 0)$ were also studied and found that the adsorption of lead and cobalt ions using the adsorbents is exothermal and spontaneous. 


\section{Nanomedicine \& Nanotechnology Open Access}

\section{References}

1. Yan Y, Dong X, Sun X, Sun X, Li J, et al. (2014) Conversion of waste FGD gypsum into hydroxyapatite for removal of $\mathrm{Pb} 2+$ and $\mathrm{Cd} 2+$ from wastewater. J Colloid Interface Sci 429: 68-76.

2. Kim TY, Park SK, Cho SY, Kim HB, Kang Y, et al. (2005) Adsorption of heavy metals by brewery biomass. Korean Journal of Chemical Engineering 22(1): 91-98.

3. Abdolali A, Ngo HH, Guo W, Lu S, Chen SS, et al. (2016) A breakthrough biosorbent in removing heavy metals: equilibrium, kinetic, thermodynamic and mechanism analyses in a lab-scale study, Sci Total Environ 542: 603-611.

4. Lee DH, Moon H (2001) Adsorption equilibrium of heavy metals on natural zeolites. Korean journal of chemical engineering 18(2): 247-256.

5. Fadzil F, Ibrahim S, Hanafiah MAKM (2016) Adsorption of lead (II) onto organic acid modified rubber leaf powder: Batch and column studies. Process Safety and Environmental Protection 100: 18.

6. Masoumi A, Hemmati K, Ghaemy M (2016) Low-cost nanoparticles sorbent from modified rice husk and a copolymer for efficient removal of $\mathrm{Pb}$ (II) and crystal violet from water. Chemosphere 146: 253-262.

7. Mondal MK (2010) Removal of Pb (II) from aqueous solution by adsorption using activated tea waste. Korean journal of chemical engineering 27(1): 144151.

8. Singha B, Bar N, Das SK (2015) The use of artificial neural network (ANN) for modeling of $\mathrm{Pb}$ (II) adsorption in batch process. Journal of Molecular Liquids 211: 228-232.

9. Wang Y, Zhang Y, Hou C, Liu M (2016) Musselinspired synthesis of magnetic polydopaminechitosan nanoparticles as biosorbent for dyes and metals removal. Journal of the Taiwan Institute of Chemical Engineers 61: 292-298.

10. Li CC, Chung HP, Wen HW, Chang CT, Wang YT, et al. (2015) The radiation resistance and cobalt biosorption activity of yeast strains isolated from the Lanyu low-level radioactive waste repository in Taiwan. J Environ Radioact 146: 80-87.
11. Kandah MI, Meunier JL (2007) Removal of nickel ions from water by multi-walled carbon nanotubes. J Hazard Mater 146(1-2): 283-288.

12. Chen C, Liu H, Chen T, Chen D, Frost RL (2015) An insight into the removal of $\mathrm{Pb}$ (II), $\mathrm{Cu}$ (II), Co (II), $\mathrm{Cd}$ (II), $\mathrm{Zn}$ (II), Ag (I), $\mathrm{Hg}$ (I), $\mathrm{Cr}$ (VI) by $\mathrm{Na}$ (I)montmorillonite and Ca (II)-montmorillonite. Applied Clay Science 118: 239-247.

13. Lin K, Pan J, Chen Y, Cheng R, Xu X (2009) Study the adsorption of phenol from aqueous solution on hydroxyapatite nanopowders. J Hazard Mater 161(1): 231-240.

14. Gupta N, Kushwaha AK, Chattopadhyaya M (2012) Adsorptive removal of $\mathrm{Pb} 2+, \mathrm{Co} 2+$ and $\mathrm{Ni} 2+$ by hydroxyapatite/chitosan composite from aqueous solution. Journal of the Taiwan Institute of Chemical Engineers 43(1): 125-131.

15. Gogoi D, Shanmugamani A, Rao S, Kumar T, Sinha P (2013) Studies on removal of cobalt from an alkaline waste using synthetic calcium hydroxyapatite. Journal of Radioanalytical and Nuclear Chemistry 298(1): 337-344.

16. Yang H, Masse S, Zhang H, Hélary C, Li L, et al. (2014) Surface reactivity of hydroxyapatite nanocoatings deposited on iron oxide magnetic spheres toward toxic metals. Journal of colloid and interface science 417: 1-8.

17. Thanh DN, Novák P, Vejpravova J, Vu HN, Lederer J, et al. (2018) Removal of copper and nickel from water using nanocomposite of magnetic hydroxyapatite nanorods. Journal of Magnetism and Magnetic Materials 456: 451-460.

18. Shoueira K, Rasha Refaat Fouadb HAA (2016) Adsorption of $\mathrm{Pb}$ (II) from seawater by hydroxyapatite nano powder.

19. Bharath G, Prabhu D, Mangalaraj D, Viswanathan C, Ponpandian N (2014) Facile in situ growth of Fe304 nanoparticles on hydroxyapatite nanorods for $\mathrm{pH}$ dependent adsorption and controlled release of proteins. RSC Advances 4(92): 50510-50520.

20. Abramov N, Turanska S, Kusyak A, Petranovska A, Gorbyk P (2016) Synthesis and properties of magnetite/hydroxyapatite/doxorubicin nanocomposites and magnetic liquids based on them. Journal of Nanostructure in Chemistry 6(3): 223-233. 


\section{Nanomedicine \& Nanotechnology Open Access}

21. Kousalya G, Gandhi MR, Sundaram CS, Meenakshi S (2010) Synthesis of nano-hydroxyapatite chitin/chitosan hybrid biocomposites for the removal of Fe (III). Carbohydrate polymers 82(3): 594-599.

22. Qi C, Tang QL, Zhu YJ, Zhao XY, Chen F (2012) Microwave-assisted hydrothermal rapid synthesis of hydroxyapatite nanowires using adenosine 5'triphosphate disodium salt as phosphorus source. Materials Letters 85: 71-73.

23. Ge F, Li MM, Ye H, Zhao BX (2012) Effective removal of heavy metal ions $\mathrm{Cd}^{2+}, \mathrm{Zn}^{2+}, \mathrm{Pb}^{2+}, \mathrm{Cu}^{2+}$ from aqueous solution by polymer-modified magnetic nanoparticles. J Hazard Mater 211: 366-372.

24. Yadav SK, Singh DK, Sinha S (2014) Chemical carbonization of papaya seed originated charcoals for sorption of $\mathrm{Pb}$ (II) from aqueous solution. Journal of environmental chemical engineering 2(1): 9-19.

25. Foroutan R, Mohammadi R, Ramavandi B, Bastanian $M$ (2018) Removal characteristics of chromium by activated carbon/ $\mathrm{CoFe}_{2} \mathrm{O}_{4}$ magnetic composite and Phoenix dactylifera stone carbon. Korean Journal of Chemical Engineering 35(11): 2207-2219.

26. Mahmoud DK, Salleh MAM, Karim WAWA, Idris A, Abidin ZZ (2012) Batch adsorption of basic dye using acid treated kenaf fibre char: equilibrium, kinetic and thermodynamic studies. Chemical Engineering Journal 181-182: 449-457.

27. Li Y, Du Q, Wang X, Zhang P, Wang D, et al. (2010) Removal of lead from aqueous solution by activated carbon prepared from Enteromorpha prolifera by zinc chloride activation. J Hazard Mater 183(1-3): 583-589.

28. Foroutan R, SKhoo F, Ramavandi B, Abbasi S (2017) Heavy metals removal from synthetic and shipyard wastewater using Phoenix dactylifera activated carbon. Desalin Water Treat 82: 146-156.
29. Podder M, Majumder C (2015) SD/MnFe204 composite, a biosorbent for As (III) and As (V) removal from wastewater: Optimization and isotherm study. Journal of Molecular Liquids 212: 382-404.

30. Yousif AM, Zaid OF, Ibrahim I (2016) Fast and selective adsorption of As (V) on prepared modified cellulose containing $\mathrm{Cu}$ (II) moieties. Arabian Journal of Chemistry 9(5): 607-615.

31. Liu R, Zhang B, Mei D, Zhang H, Liu J (2011) Adsorption of methyl violet from aqueous solution by halloysite nanotubes. Desalination 268(1-3): 111116.

32. Foroutan R, Esmaeili H, Rishehri SD, Sadeghzadeh F, Mirahmadi S, et al. (2017) Zinc, nickel, and cobalt ions removal from aqueous solution and plating plant wastewater by modified Aspergillus flavus biomass: A dataset. Data in brief 12: 485-492.

33. Forutan R, Ehsandoost E, Hadipour S, Mobaraki Z, Saleki M, et al. (2016) Kinetic and equilibrium studies on the adsorption of lead by the chitin of pink shrimp (Solenocera melantho). Entomol Appl Sci Lett 3: 2026.

34. Ngah WW, Fatinathan S (2010) Adsorption characterization of $\mathrm{Pb}$ (II) and $\mathrm{Cu}$ (II) ions onto chitosan-tripolyphosphate beads: kinetic, equilibrium and thermodynamic studies. J Environ Manage 91(4): 958-969.

35. El-Ashtoukhy ES, Amin NK, Abdelwahab O (2008) Removal of lead (II) and copper (II) from aqueous solution using pomegranate peel as a new adsorbent. Desalination 223(1-3): 162-173.

36. Ngah WW, Ab Ghani S, Kamari A (2005) Adsorption behaviour of $\mathrm{Fe}$ (II) and Fe (III) ions in aqueous solution on chitosan and cross-linked chitosan beads. Bioresour Technol 96(4): 443-450. 